\title{
FUNDAMENTOS FILOSÓFICOS DA PROTEÇÃO AMBIENTAL
}

Arnaldo Moraes Godoy

SUMÁRIO: 1. Introdução. 2. A Retórica Antropocêntrica. 3. O Controle Filosófico da Natureza. 4. O Passado e o Futuro. 5. Conclusão. 6. Bibliografia.

SUMMARY: 1. Introduction. 2. The Rhetorical Antropocentric. 3. The Philosophical Control of the Nature, 4. The Past and the Future. 5. Conclusion. 6. Bibliography.

SUMARIO: 1. Introducción. 2. El Retórico Antropocêntrico. 3. El Controle Filosófico de la Naturaleza. 4. El Pasado y el Futuro. 5. Conclusión. 6. Bibliografia.

RESUMO: O presente trabalho considera os fundamentos filosóficos da proteção ambiental, evidenciando razões antropocèntricas, em que pese esforço mais contemporâneo para justificativas biocêntricas, que focalizam a natureza por seus intrínsecos valores. $O$ excerto também vislumbra fundamentos políticos e econômicos, no modelo ambientalista brasileiro, utilizado para captação de recursos externos.

ABSTRACT: The present research considers the philosophy basis of environment protection showing anthropologic reasons. Biological justifications with contemporary bases focus the nature's most intrinsic values. The compiled also analyses the economic and political bases in the Brazilian environment model used to attract external resource. 
RESUMEN: La investigación presente considera la base de la filosofia de la exhibición de protección del ambiente per rezones antropológicos. Las justificaciones biológicas con el enfoque de las bases contemporáneo en la naturaleza de la mayoría de los valores intrínsecos. Los compilamos también las vislumbres de las bases económicas y políticas en el modelo de ambiente brasileño atráan el recurso externo.

PALAVRAS-CHAVES: Proteção Ambiental. Justificativas. Antropocentrismo. Biocentrismo. Marketing Ecológico.

KEY-WORDS: Environmental protection. Justification. Anthropocentrism. Biocentrism. Ecologic marketing.

PALABRAS-LLAVE: Protección del ambiente La justificación. El antropocentrismo. El biocentrismo. Comercialización ecológica.

\section{Introdução}

Efeito estufa, biodiversidade, reflorestamento, aumento populacional, buraco na camada de ozônio, desenvolvimento sustentável, entre outras, são expressões qualificadas por linguagem universal de uso geral, recorrentes na contemporaneidade. $\mathrm{O}$ ambientalismo parece ganhar corações e mentes de uma vanguarda verde, que prescreve como a natureza deve ser protegida. Explicitar os porquês da proteção ambiental, sob uma perspectiva filosófica, eis o motivo do presente trabalho'.

Verifica-se clivagem conceitual no movimento ecológico. Um segmento mais social preocupa-se com legalismo prescritivo que determina como cuidar-se do meio ambiente. Parcela mais crítica concentra-se nos porquês da aludida proteção, desenhando-se uma ética da terra, um ambientalismo holístico. Esse grupo também convive com uma dicotomia. Para os mais conservadores, protagonistas de um ambientalismo pouco profundo (shallow environmentalism) a proteção ambiental decorre do fato de que a natureza tem valor instrumental para nós, seres humanos; trata-se da concepção dominante ${ }^{2}$. A esse intenso antropocentrismo contrapöe-se um biocentrismo insurgente, que reconhece direitos intrínsecos à própria natureza, hostilizando o pragmatismo de matiz humanista ${ }^{3}$.

\footnotetext{
Indica-se a obra do Professor Alexander Gillespie, da Universidade de Waikato, Nova Zelandia, "International Emvironmental Law Policy and Ethics" como texto inspirador do presente excerto.

${ }^{z}$ Alexander Gillespie, op. cit, pág. 2.

${ }^{3}$ Paulo de Bessa Antunes, Direito Ambiental, pág. 20 e ss.
} 
Conotações mais sociológicas denunciam o uso do ambientalismo por parte de injunções políticas orquestradas para a captação de recursos externos e de simpatias ensejadoras de votos, prestígio, poder ${ }^{4}$.

\section{A Retórica Antropocêntrica}

A tradição ocidental coloca o homem no centro do universo, medida de todas as coisas, na consagrada expressão de Protágoras, tão afeto à precisão e propriedade de definições e conceitos ${ }^{6}$. Por conta dessa ilusão conceitual colocamo-nos no centro de tudo e não no centro de uma vida particular ${ }^{7}$, atitude conceitual refratária a concepções mais harmônicas, típicas do pensamento oriental, substrato das tradições chinesas, japonesas e indianas. $\mathrm{O}$ antropocentrismo pode traduzir um chauvinismo humano, comparável a idiossincrasias outras, sexuais, racionais, nacionalistas, xenófobas. É comportamento típico de quem desenhou Deus a sua imagem e semelhança, valendo-se da retórica para afirmar justamente o contrário.

Platão reporta-se a Prometeu como emancipador da grei humana, após subtrair a ciência de Hefaistos e de Palas Atenas?. No Timeu, Platão refere-se ao homem como raça superior ${ }^{10}$. Aristóteles aponta o natural desejo que o homem tem de conhecimento como traço que nos distingue dos animais, que vivem de aparências ${ }^{11}$. Para o estagirita, o homem é conhecimento, sabedoria, sagacidade ${ }^{12}$. Agostinho concebe o homem como criatura abençoada, presente de Deus, luz ${ }^{13}$. Tomás de Aquino afirma que o homem excede os animais, em razão e inteligência ${ }^{14}$. Para o doutor angélico, o homem transcende as agruras da sobrevivência e obtém prazer no próprio trabalho ${ }^{15}$. Descartes proclama a perfeição da inteligência humana, equipolando sua inteligência a dos homens ordinários ${ }^{16}$. Locke refere-se a Adão (o homem) como detentor de força e razão ${ }^{17}$. Montesquieu credita ao homem conhecimento, enquanto poder, intrínseco

\footnotetext{
Solange S. Silva Sánchez, Cidadania Anbiental: Novos Direitos no Brasil, pág. 157 e ss.

"John Burnet, L'Amore de la Philosophie Grecque, pág. 190.

"León Robin, La Pensée Grecque, pág. 170.

* Alexander Gillespie, op cit, pag 14.

- Surya Prakash Sinha, Juxisprudence-Legal Philosoplyy, pág. 22 e $\$$.

Plato, Protagoras, pág. 44.

10 Plato, Timaeus, pág. 453.

11 Aristotle, Metaphysics, pág. 499

${ }^{12}$ Aristotle, History of Animals, pag. 114.

St. Augustine, Confessions, pág. 113.

thomas Aquinas, Summa Theologica, pag. 15

is Thomas Aquinas, op. cit., pág. 106.

is Descartes, Discourse on the Method, pag. 41.

John Locke, Concening Civil Government, pag. 36.
} 
à existência ${ }^{18}$. Rousseau diferencia o homem das outras criaturas, por causa do livre-arbítrio ${ }^{19}$, determinado infalivelmente pela razão, na imagem de Kant ${ }^{20}$, promotora do desenvolvimento e da emancipação, no passo de John Stuart Mill ${ }^{21}$. Hegel lembra que o homem tem o poder de destruir-se, condição que os animais não possuem ${ }^{22}$. Tolstoy fundamenta o fim de "Guerra e Paz" sob impressão de que o objeto da história não é o livrearbítrio, mas a representação humana do mesmo ${ }^{23}$. Dostoievsky concebe Ivan Karamazov conturbado com um estado depressivo que não pode explicar, que lhe retira esperanças de vida, que só vale a partir das expectativas que a individualidade formula ${ }^{24}$.

O antropocentrismo radica nos racionalistas primitivos, que separaram a humanidade da natureza, o mortal do imortal, premissa abraçada pelo cristianismo, que cindiu o mundo físico do universo mental, centro da dúvida radical de Descartes. O cristianismo sacralizou o individualismo, tônica do protestantismo de primeira leva, ambientado no luteranismo e no calvinismo, a aceitarmos os postulados da sociologia weberiana ${ }^{25}$. O "cogito" de Descartes, mais alto ponto do individualismo filosófico, projeta-se na "Aufklarung" oitocentista. Esse individualismo encontra-se na constituição norte-american $a^{26}$, arrastando-se até perspectivas filosóficas mais recentes, com estações em Ronald Dworkin ${ }^{27}$ e implementado na pragmática do thatcherismo e do reaganismo.

A tradição ocidental dicotomizou homem e natureza, com fundamento num logocentrismo definidor de que só o homem pode falar, obviedade detectada por Hobbes, Descartes, Hegel, Nietzsche e Wittgenstein ${ }^{28}$. Só o homem vive a moralidade. É mau quando traços animais tomam conta de si, a propósito da imagem de Hobbes, para quem o homem é o lobo do homem ${ }^{29}$.

\footnotetext{
1* Montesquieu, The Spirit of Laws, pág. 2.

19 Jean-Jacques Rousseau, On the Origin of Inequality, pág. 337.

20 Immanuel Kant, Fundamental Principles of the Metaphysic of Morals, pág. 265.

2] John Stuart Mill, On Liberty of Individuality, pág. 297.

2 Georg Wilhelm Friedrich Hegel, The Philosophy of Rights, pág. 24.

23 Tolstoy, War and Peace, pág, 690.

24 Dostoievsky, The Brothers Karamazov, pág. 137.

25 Max Weber, A Etica Protestante e o Espírito do Capitalismo.

${ }^{26}$ Kermit L. Hall et allii, American Legal History, pág. 69 e ss.

${ }_{27}$ Ronald Dworkin, Taking Rights Seriously, pág. 266 e ss.

${ }^{28}$ Alexander Gillespie, op. cit., pág. 10.

29 Alexander Gillespie, op. cit., loc. cit.
} 


\section{O Controle Filosófico da Natureza}

Relativizada e subordinada, a natureza é objeto de controle, e não de comunhão. A humanidade detentora da ciência arroga-se protagonista de messiânia tarefa. Seu papel é de dominar o mundo, e perspectivas frankfurtianas que radicam em Horkheimer, Adorno, Benjamim e Marcuse cuidam dessa denúncia. A legislação ambiental baseia-se nessa diretiva conceitual. Em 1992 a declaração do Rio confirmou tal presunção, fixando o homem no centro da política ambiental. Relega-se o que não é humano à categoria de "recursos", paradigma que consubstancia ética decorrente de auto-imagem ideologicamente comprometida com um freudianismo explícito de homem dominante.

A sobrevivência e a prosperidade da humanidade vinculam-se à saúde da biosfera (a valermo-nos de um conceito hipocrático) e à interdependência de ecossistemas. Em termos mais explícitos, a humanidade protege a natureza porque a natureza protege a humanidade. Um temor apocalíptico oxigena o ambientalismo. Surge uma racionalidade econômica a gerir o meio-ambiente, traduzida em cálculos de custo e beneficio ${ }^{30}$, reduzindo-se a proteção ambiental ao dinheiro ${ }^{31}$. Questões ambientais tendem a ser assimiladas pela economia; a identidade não é apenas glotológica, aceito que ecologia e economia vinculam-se a raiz idêntica, o "oikos" da fala ática. A análise racional do meio-ambiente preocupa-se com a produtividade, com a obtenção de maior utilidade com um mínimo de ineficiência ou perda. Apropria-se do ideário de Bentham e protege-se o meio ambiente porque ele é economicamente útil. Dada a relativização da utilidade, emergem antinomias, a exemplo do conflito entre Nova Zelândia e Noruega, a propósito da caça as baleias. Se a natureza nada fez de supérfluo, como pretendeu Aristóteles ${ }^{32}$, o homem a valoriza por um critério de utilidade. Não fosse assim, não cogitaria de matar o vírus da varíola.

Uma ecoteologia insurgente postula justificativas religiosas para a proteção ambiental. Assume-se o panteísmo de Spinoza, que identificava Deus na natureza. Formata-se um ambientalismo espiritual. São Francisco de Assis ganha foros de padroeiro da ecologia, por conta de apologias ao irmão sol, à irmã lua, à irmã água, ao irmão fogo, este último belo, jocundo, robusto, forte ${ }^{33}$. O ambientalismo passa a ser captado num contexto bíblico, com paragens em Gênesis (1:26, 1:28), Lucas (16:2) e Mateus (6:28-29).

\footnotetext{
* Alan B. Morrison (edit), Fundamentals of American Law, pág. 502 e ss.

3) Roger W. Findley e Daniel Farber, Environmental Law, pág. 108.

Alexander Gillespic, op.cit, pag. 48 .

33 Săo Francisco de Assis, Cântico das Criaturas, pág. 136.
} 
Premissas estéticas também autorizam a proteção ambiental. A beleza das montanhas, o pôr-do-sol, o torvelinho de um riacho consubstanciam riquezas que não suscitam aferição monetária. A crematística aristotélica não ousa aferir a axiologia do natural. A bambificação da natureza conheceu seu auge na estética romântica, que pranteou o meio-ambiente em Keats, Byron, Shelley e Rousseau, o caminhante solitário que fazia devaneios numa Genebra ainda bucólica e pastoral. Para a tradição marxista a estética é experiência social e culturalmente determinada, prenhe de conotações ideológicas, calibrada pela necessidade e pelo acaso ${ }^{34}$. Aceita-se o valor estético da natureza como permanente, percebido por Pausânias e por todos os viajantes, dos mais antigos aos cativos da contemporânea indústria do turismo de massa. Não se procura um foco de inspiração, busca-se um ângulo para fotografar.

Prolegômenos culturais exigem a proteção ambiental, em nome da defesa do habitat natural e cultural de populações nativas, e a justificativa fora assimilada pelo princípio 22 da Declaração do Rio. Identidades nacionais de referencial ambiental desencadeiam medidas protetivas, a exemplo da luta pela manutenção do canguru australiano, da águia norteamericana, da capivara do setentrião brasileiro. Concebe-se uma globalização rousseauniana do nobre selvagem, esquecendo-se que comunidades nativas não oferecem bons exemplos de harmonia ecológica. Nem todas elas são ambientalmente benignas. "Inuits" caçam baleias. A antropologia registra canibalismos, circuncisão de mulheres, genocídios.

$\mathrm{O}$ antropocentrismo autoriza a menção de valores recreacionais como justificativos da proteção ambiental, desenhando o "greentourism". O ecoturismo promove o desfrute de áreas ecologicamente equilibradas. $\mathrm{O}$ turismo ecológico permite o deleite em áreas ecologicamente ameaçadas pela destruição, maltratadas por pescadores vitaminados pelo álcool e entorpecidos pela nicotina. Pretendem a reconciliação com uma natureza id́lica, que não passa de pretexto para a fuga de uma existência urbana banal, esgotada nos serões de uma televisão que idiotiza e nivela diferenças. Cogita-se da manutenção da selva, capítulo mais recente de investidas imperialistas ocidentais.

${ }^{3+}$ Marilena Chauí, Convite à Filosofia, pág. 264. 


\section{O Passado e o Futuro}

$\mathrm{O}$ antropocentrismo superlativo defende a proteção ambiental $\mathrm{em}$ nome do vago conceito de "gerações futuras". A Lei $\mathrm{n}^{\underline{x}} 9.433 / 97$ indica como objetivo da política nacional de recursos hídricos assegurar-se à atual e às "futuras gerações" a necessária disponibilidade de água. $\mathrm{O}$ artigo 225 da Constituição Federal de 1988 propõe o direito ao meio ambiente ecologicamente equilibrado às presentes e "futuras gerações". Defende-se a educação ambiental como um necessário e efetivo compromisso político dos administradores com as "futuras gerações" $"$. A preocupação com as "futuras gerações" é típica do pós-guerra. Freqüenta a Convenção Internacional de Regulamentação da Pesca da Baleia (1946), a Declaração de Estocolmo (1972) e a Declaração do Rio, princípio 3 (1992). Alexander Gillespie imagina um ombusdman para as "futuras gerações" ${ }^{36}$. O mote traduz auto-transcendência, atemporalidade. Gerações do passado teriam feito sacrifícios para as presentes e futuras. Porém nada sabemos a propósito das necessidades do amanhã. Há pouco mais de dois séculos não se pensava dos valores do petróleo e do plutônio. A preocupação com as "futuras gerações" tem certo sabor freudiano e consubstancia eloqüentemente mais uma face do antropocentrismo dominante.

O biocentrismo inspira uma ética do equilibrio, que tem como certa a premissa que confere validade à preservação da integridade, estabilidade e beleza da comunidade biótica. É um erro comportar-se de outra forma. Por vias transversas submete-se o individualismo ao bem geral. Posições não antropocêntricas reconhecem intrínsecos valores na natureza, valendo-se de paradigmas holísticos, reconhecendo direitos dos animais. Rejeita-se o paradoxo de Joel Fainberg, para quem áryores não têm desejos ou objetivos, não tem consciência, não têm portanto satisfações ou frustrações, dor ou prazer. Nos termos da curiosa imagem de Fainberg, as árvores não poderiam sofrer. $\mathrm{O}$ homem não poderia ser cruel com elas ${ }^{37}$. Considera-se a moral dos animais, desenha-se uma ética da terra. Não nos interessa se são racionais, se não podem falar. Nos cabe garantir que eles não sofram. Se direitos existem, eles não podem ser dados aos homens e negados aos animais, desde que o mesmo senso de justiça e compaixão aplica-se em ambos os casos. Dor é dor, não interessa onde ${ }^{38}$.

\footnotetext{
3 Wanderley Retelho Filho, Guia Pútico de Direito Ambiental, pág. 3.

str Alexander Gillespie, op. cit., pág. 110.

${ }^{37}$ Alexander Gillespic, op. cit., pág. 152

Alexander Gillespie, op. cit., pág. 138.
} 
A par da clivagem conceitual que separa o antropocentrismo do biocentrismo, um outro fator, menos filosófico e mais político, tende a justificar o ambientalismo em países em desenvolvimento, metáfora que qualifica nossa condição periférica. Inegáveis os vínculos entre política econômica e ambiental e política social ${ }^{39}$. No entanto, o oportunismo tão caro à prática política apropria-se do discurso ambientalista, fazendo da miragem amazônica um refém ${ }^{40}$, forte na aceitação da biodiversidade como patrimônio global. Acenam-se com projetos de factibilidade duvidosa, buscam-se recursos para intervenções que não saem do papel, comercializa-se a esperança em troca de prestígio, fama e alguns dinheiros.

\section{Conclusão}

Conclui-se que o antropocentrismo é o substrato filosófico da proteção ambiental. Radica no auto-interesse, em razão econômicas, em justificativas religiosas, estéticas, culturais, recreacionais. Constrói-se o mito das "futuras gerações". Formata-se uma reação biocêntrica, ainda não totalmente esclarecida, com as cores de um antropocentrismo retificado, mitigado, emancipado. Percebe-se uma apropriação mercadológica, que transita num discurso messiânico, apocalíptico, escatológico, que alberga oportunistas, que vendem uma bandeira, por alguns minutos de fama, comprovando o vaticínio de Andy Warhol.

\section{BIBLIOGRAFIA}

ADLER, Mortimer J. (edit). The Great Ideas. A Syntopicon of Great Books of the Western World. Chicago: Britannica, 1952.

ANTUNES, Paulo de Bessa. Direito Ambiental. Rio de Janeiro: Lumen Juris, 2000. AQUINAS, Thomas. Great Books of the Westem World. Chicago: Britannica, 1952. ARISTOTLE. Great Books of the Western World. Chicago: Britannica, 1952. ASSIS, São Francisco de. I Fioretti e Cântico das Criaturas. Rio de Janeiro: Ediouro, s.d. BURNET, John. L'Aurore de la Philosophie Grecque. Paris: Payot, 1952. DERANI, Cristiane. Direito Ambiental Econômico. São Paulo: Max Limonad, 1997.

\footnotetext{
39 Cristiane Derani, Direito Ambiental Econômico, pág. 91 e ss.

"Wolange S. Silva-Sanchez, op. cit., pág. 169.
} 
DESCARTES, René Great Books of the Westem World Chicago: Britannica, 1952. DOSTOIEVSKY, Fyodor Mikhailovich. Great Books of the Western World. Chicago: Britannica, 1952.

DWORKIN, Ronald. Talking Rights Seriously, Cambridge: Haward University Press, 1999.

FINDLEX, Roger W. e FARBER, Daniel. Environmental Law. St. Paul, Minn.: West Group, 2000.

GILLESPIE, Alexander. International Environmental Law Policy and Ethics. New York: Oxford University Press, 1997.

HALL, Kermit L., et alii. American Legal History. New York: Oxford University Press, 1996.

HEGEL, Georg Wilhelm Friedrich. Great Books of the Western World. Chicago: Britannica, 1952.

KANT, Immanuel. Great Books of the Westem World. Chicago: Britannica, 1952. LOCKE, John. Great Books of the Western World. Chicago: Britannica, 1952. MIL, John Stuart. Great Books of the Western World. Chicago: Britannica, 1952. MONTESQUTEU. Great Books of the Westem World. Chicago: Britannica, 1952. MORRISON, Alan B.. Fundamentals of American Law. New York: Oxford University Press, 2000.

PLATO. Great Books of the Western World. Chicago: Britannica, 1952.

REBELLO FILHO, Wanderley e BERNARDO, Christianne. Guia Prático de Direito Ambiental. Rio de Janeiro: Lumen Juris, 1999.

ROBIN, Léon. La Pensée Grecque. Paris: Albin Michel, 1948.

ROUSSEAU, Jean-Jacques. Great Books of the Western World. Chicago: Britannica, 1952.

SILVA-SÁNCHEZ, Solange S.. Cidadania Ambiental: Novos Direitos no Brasil. São Paulo: Humanitas/USP, 2000.

SURYA, Surya Prakash. Jurisprudence-Legal Philosophy. St. Paul, Minn.:West Publishing, 1993.

ST. AUGUSTINE Great Books of the Westem World. Chicago: Britannica, 1952. TOLSTOY, Leo. Great Books of the Western World. Chicago: Britannica, 1952. WEBER, Max. A Ética Protestante e o Espírito do Capitalismo. São Paulo: Livraria Pioneiro Editora, 1983. 